Pacific

Northwest

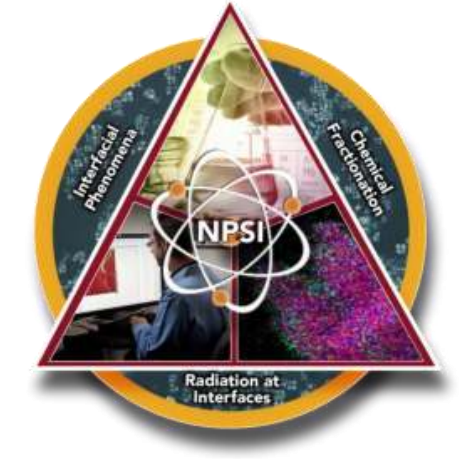

ACS March Meeting 2020

Interfacial radiation damage resistance in oxide thin film heterojunctions: An atomic perspective

M. Sassi ${ }^{1}$, T. Kaspar ${ }^{1}$, L. Shao ${ }^{2}$, J. Gigax ${ }^{3}$, V. Shutthanandan ${ }^{4}$, K. M. Rosso', and S. R. Spurgeon

${ }^{1}$ Physical and Computational Sciences Directorate, Pacific Northwest National Laboratory, Richland, WA 99354, USA 2Department of Nuclear Engineering, Texas A\&M University, College Station, TX 77843, USA 3Los Alamos National Laboratory, Los Alamos, NM 87545, USA ${ }^{4}$ Environmental Molecular Sciences Laboratory, Pacific Northwest National Laboratory, Richland, WA 99354, USA

${ }^{5}$ Energy and Environment Directorate, Pacific Northwest National Laboratory, Richland, WA 99354, USA

\title{
ENERGY BATHELIE
}

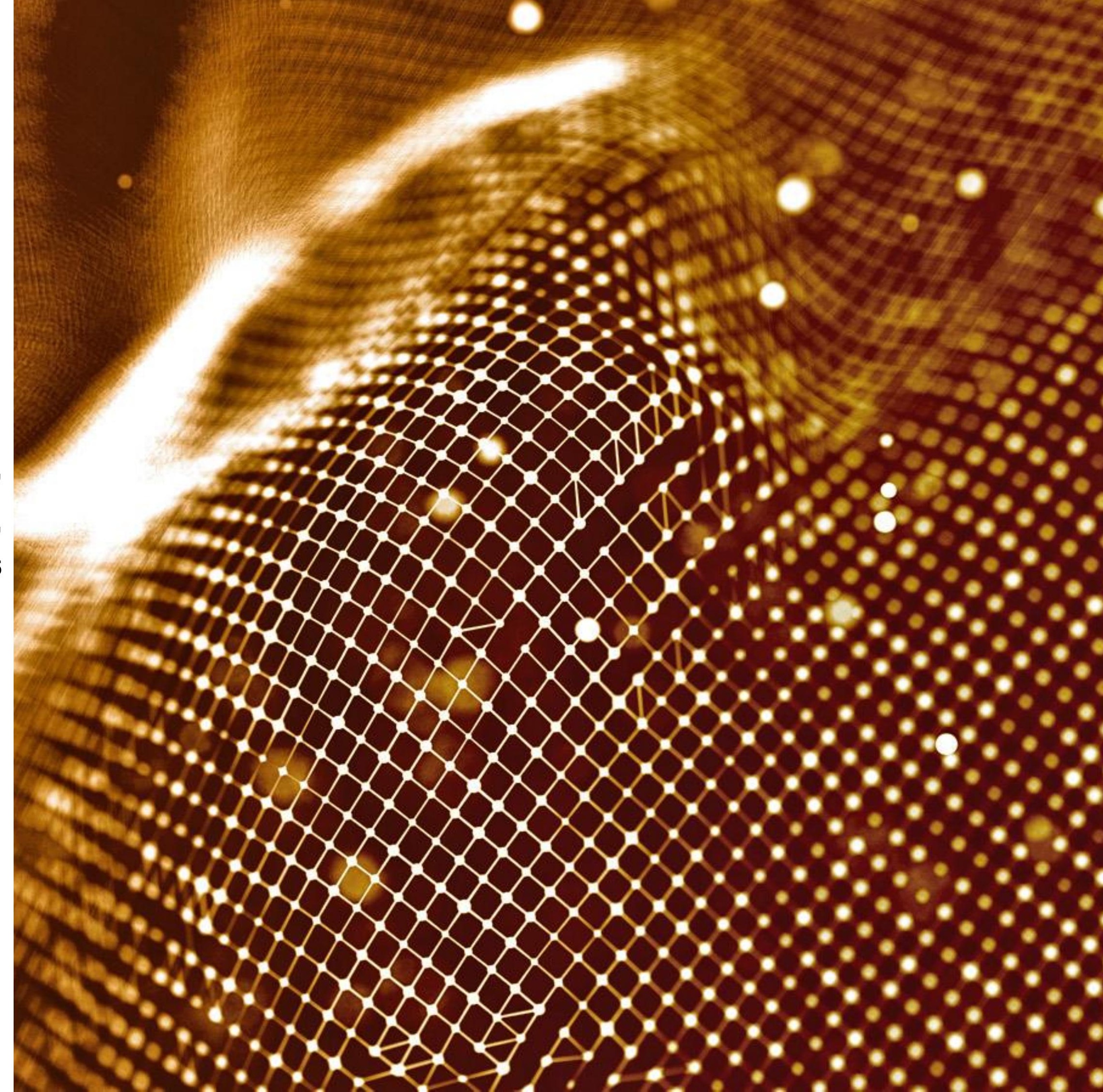


Radiation-Induced Defect Formation in Oxides Impacts a Range of DOE Research Areas

Pacific

Northwest
Aerospace

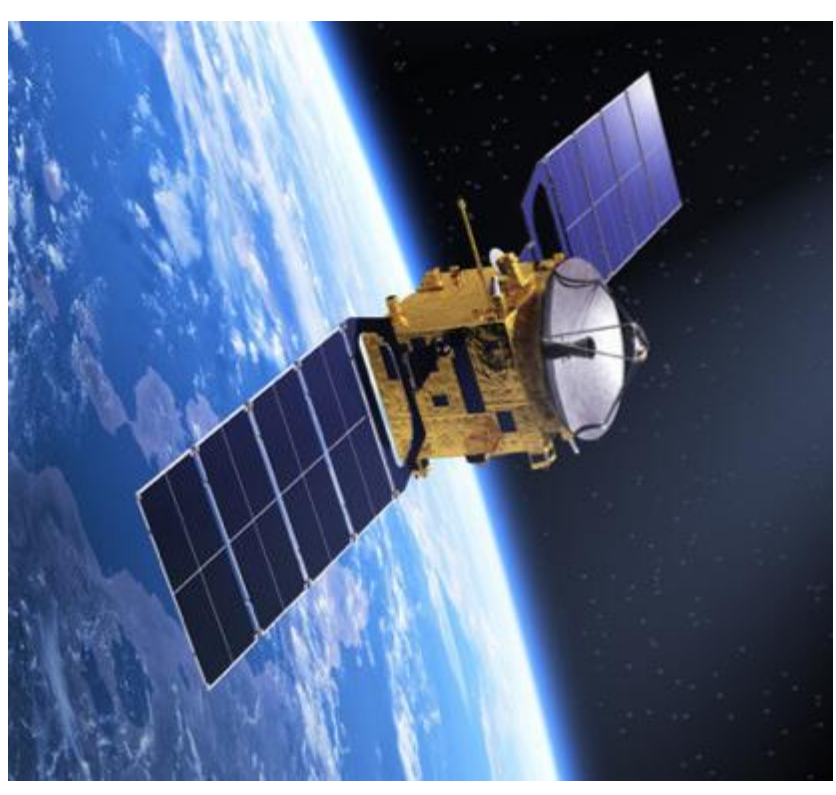

Device Performance DOE-BES
Electronics

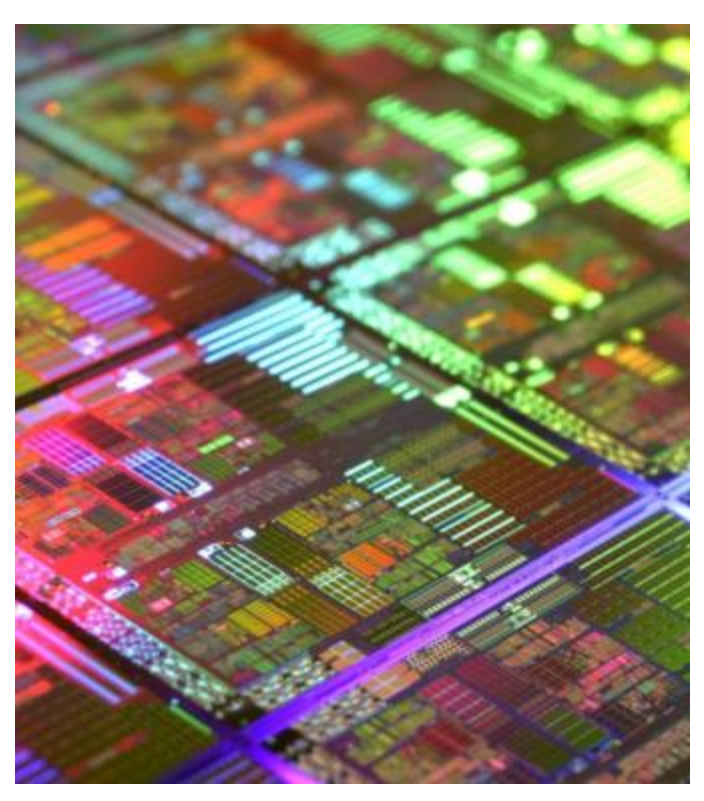

Ion Interactions DOE-BES 
Pacific

Northwest

NATIONAL LABORATORY

Example of use and applications:

- Oxidation catalysts

- Thermal barrier coating

- Immobilization of actinides from spent nuclear fuel

Exposition to extreme environment:

- Microstructure evolution

- Phase transitions

- Degradation of physical and chemical properties

$\square$ Understand of the response of pyrochlores:

- Electron, ion or pulsed laser irradiation experiments

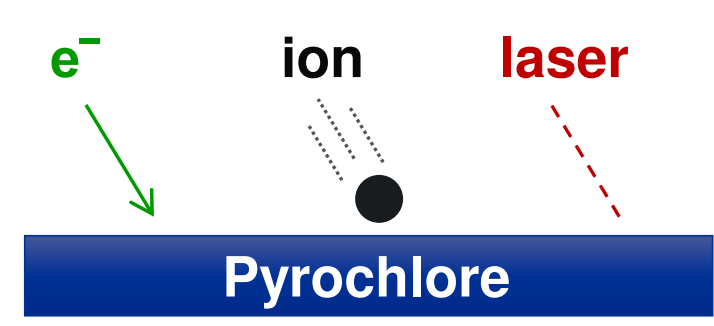

Amorphization:

- Internal radiation (actinide a-decay)

- External ion-irradiation 


\section{Local Evolution of Ion-Irradiation-Induced Amorphization}

Pacific

Northwest

NATIONAL LABORATORY

$\square$ Experimental observations upon $1 \mathrm{MeV} \mathrm{Zr}^{+}$irradiation:

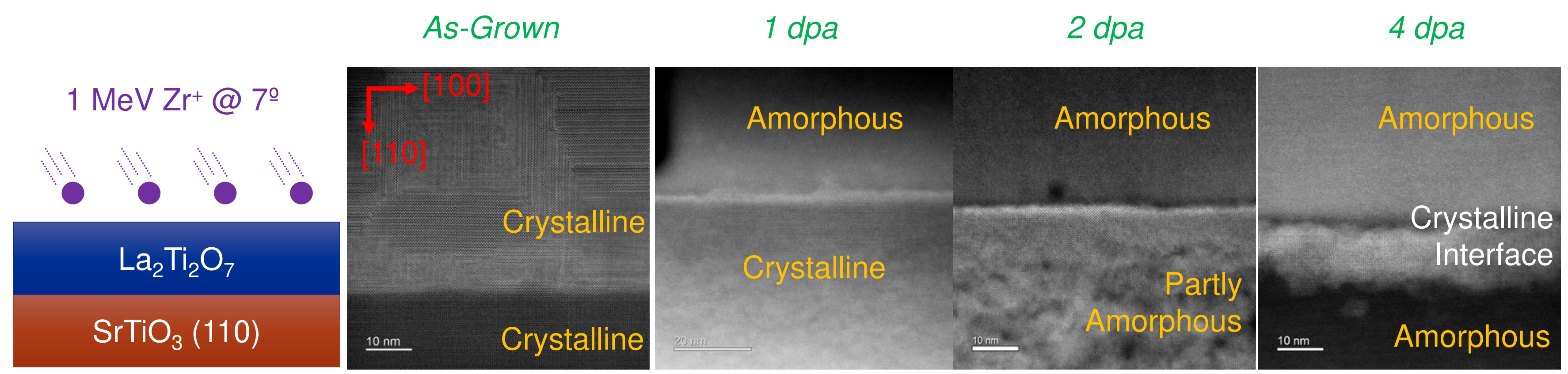

- Amorphization of film observed before the substrate

- Appearance of a crystalline band at the film/substrate interface 
$\square$ Focus on the interfacial changes (PACBED analysis):
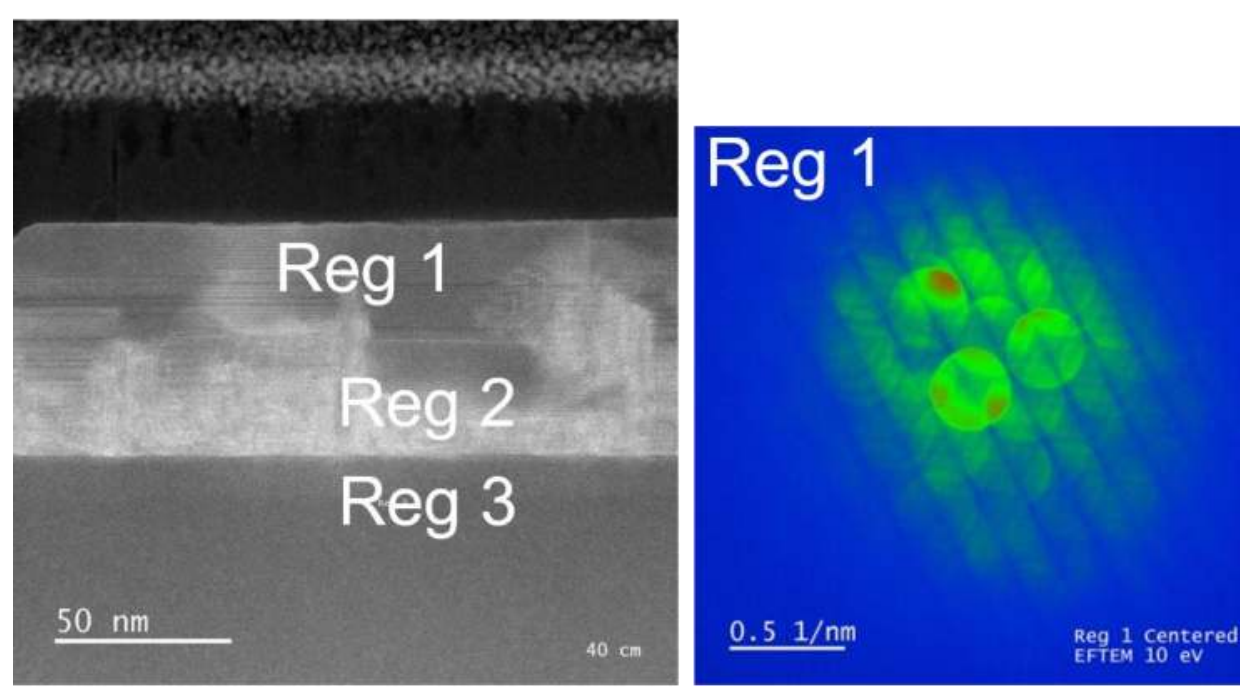

Before irradiation
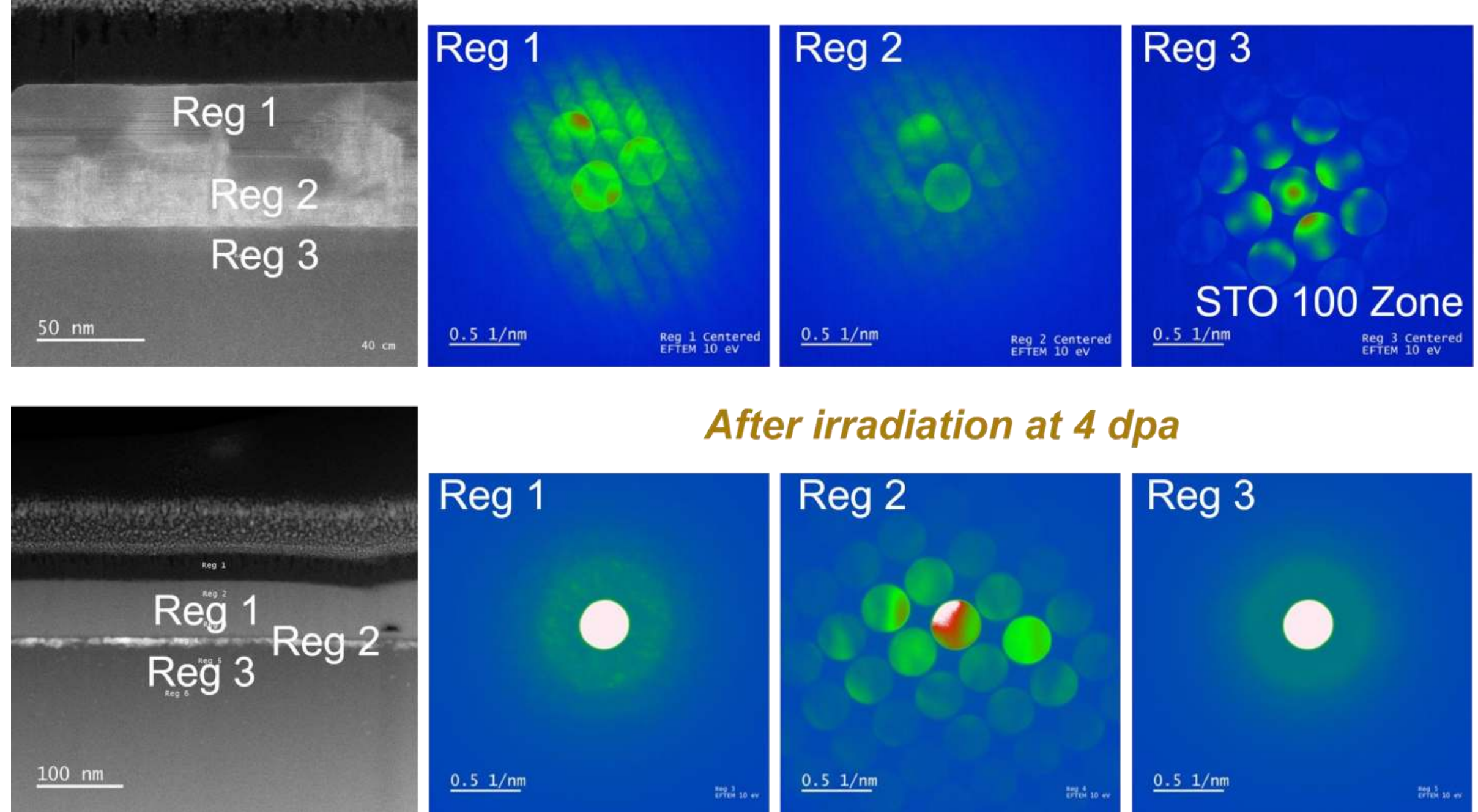

$\operatorname{Reg} 1$

After irradiation at 4 dpa

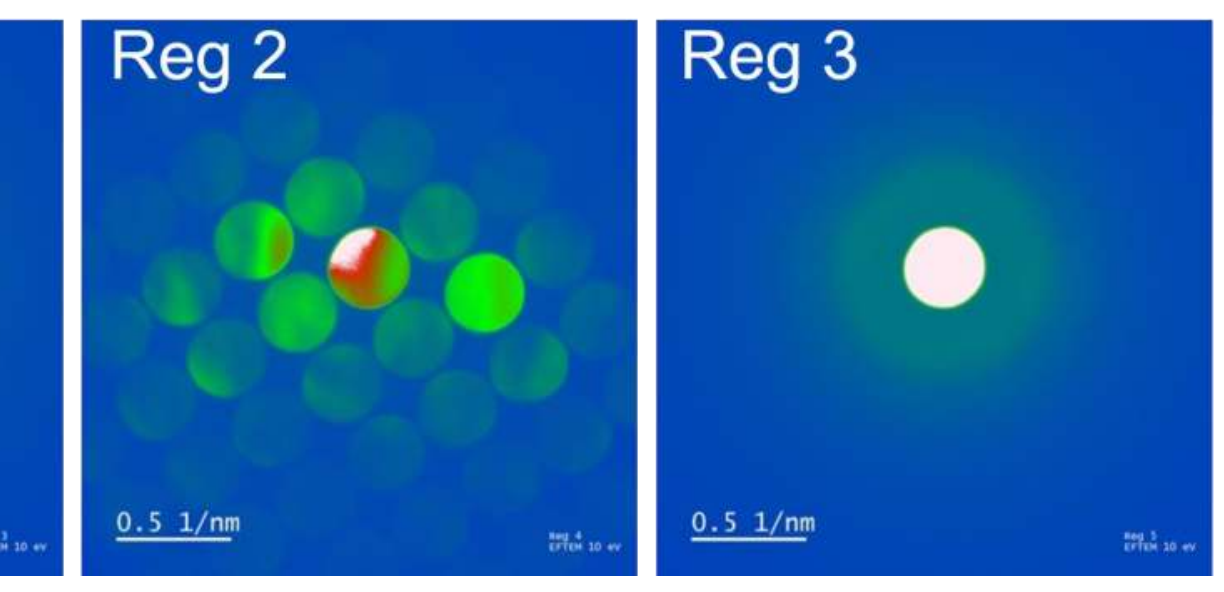

- The interface remains crystalline even at 4 dpa 


\section{Evolution of Interface Composition}

Pacific

Northwest

NATIONAL LABORATORY

\section{$\square$ EDS analysis:}

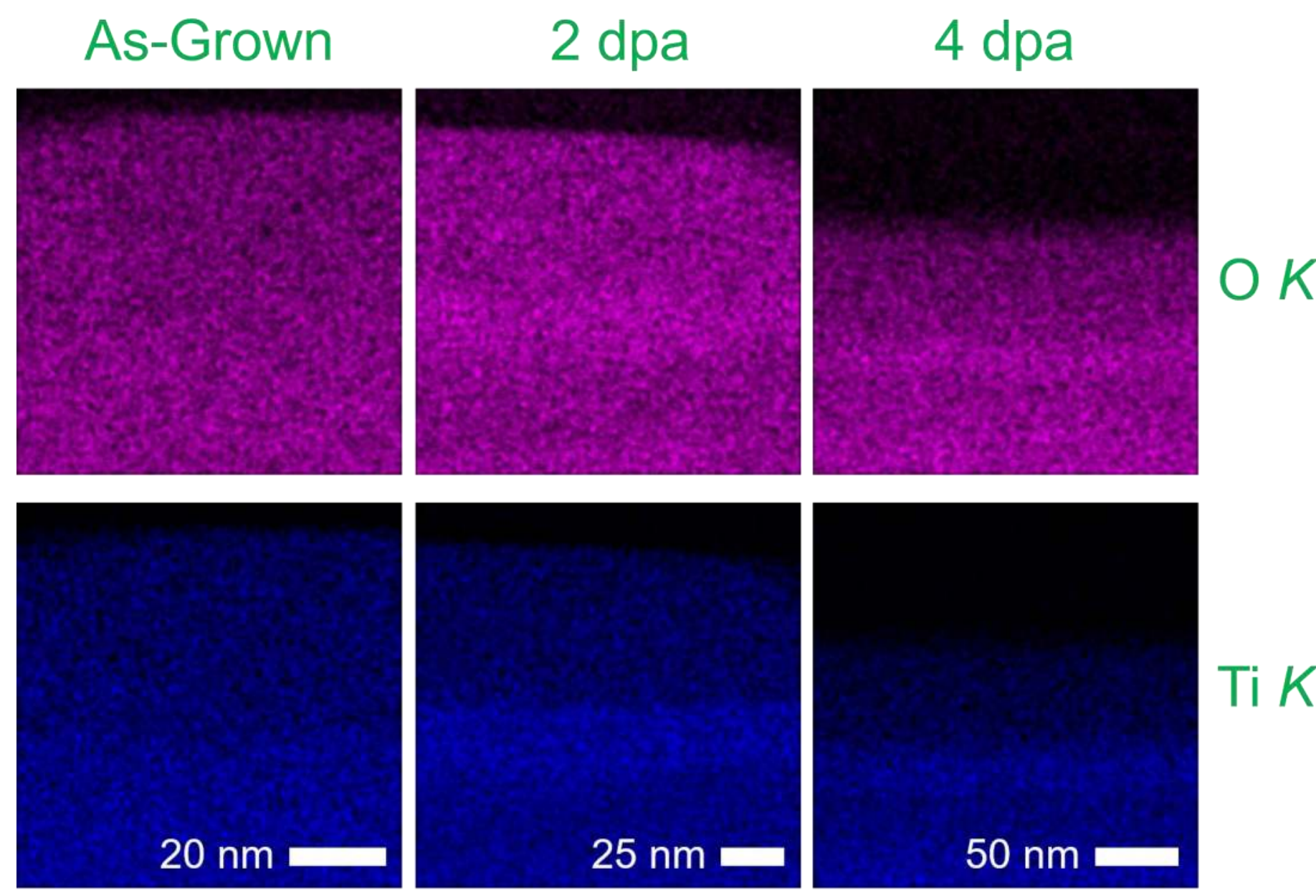

- EDS maps show a relative increase in $\mathrm{Ti}$ and $\mathrm{O}$ content at the interface with increasing dose.

- This suggests that defect migration to the interface may help promote stability. 


\section{Evolution of the Interface Structure}

Pacific

Northwest

NATIONAL LABORATORY

\section{EELS analysis on LTO As-Grown:}

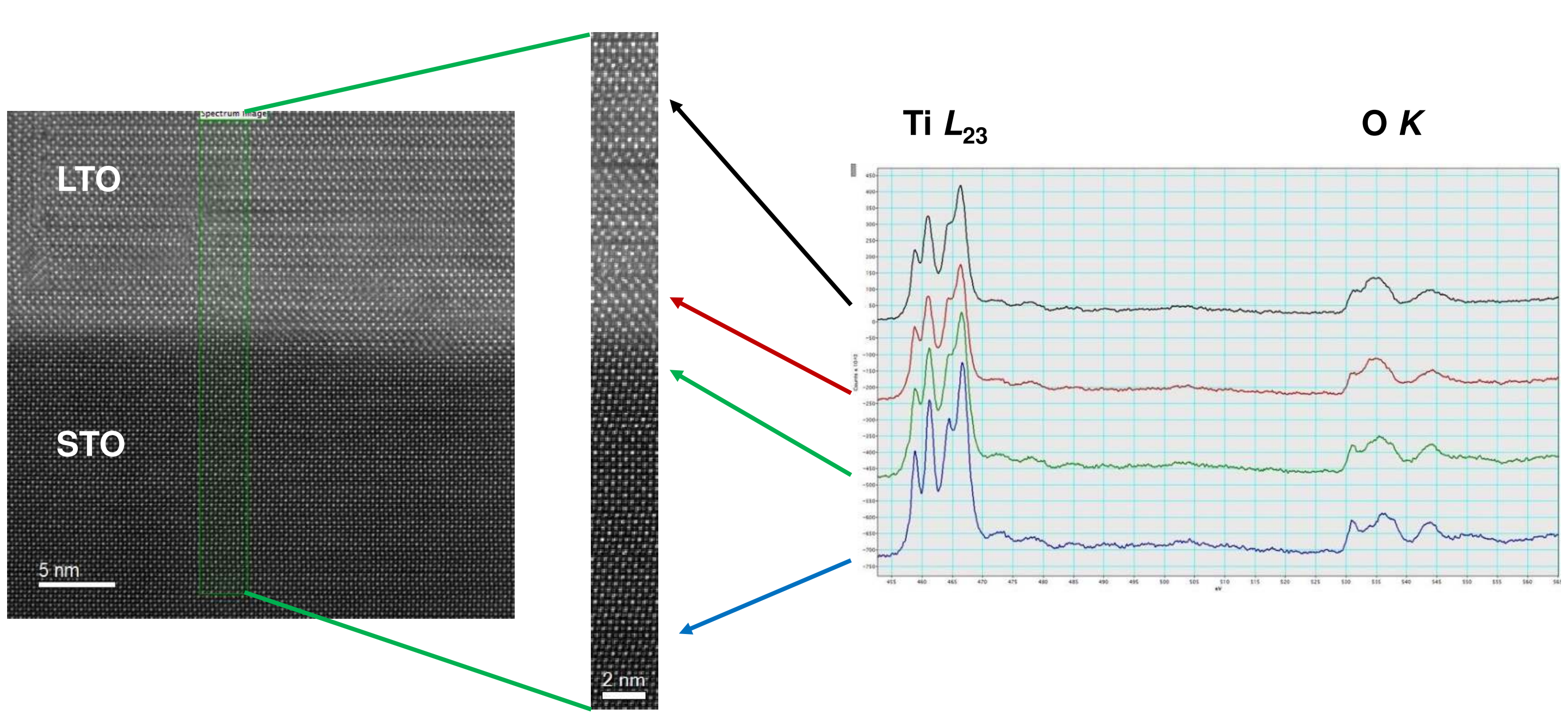

- STO fine structure is consistent with bulk STO and LTO from the literature 


\section{Evolution of the Interface Structure}

Pacific

Northwest

NATIONAL LABORATORY

\section{EELS analysis on LTO at 4 dpa:}

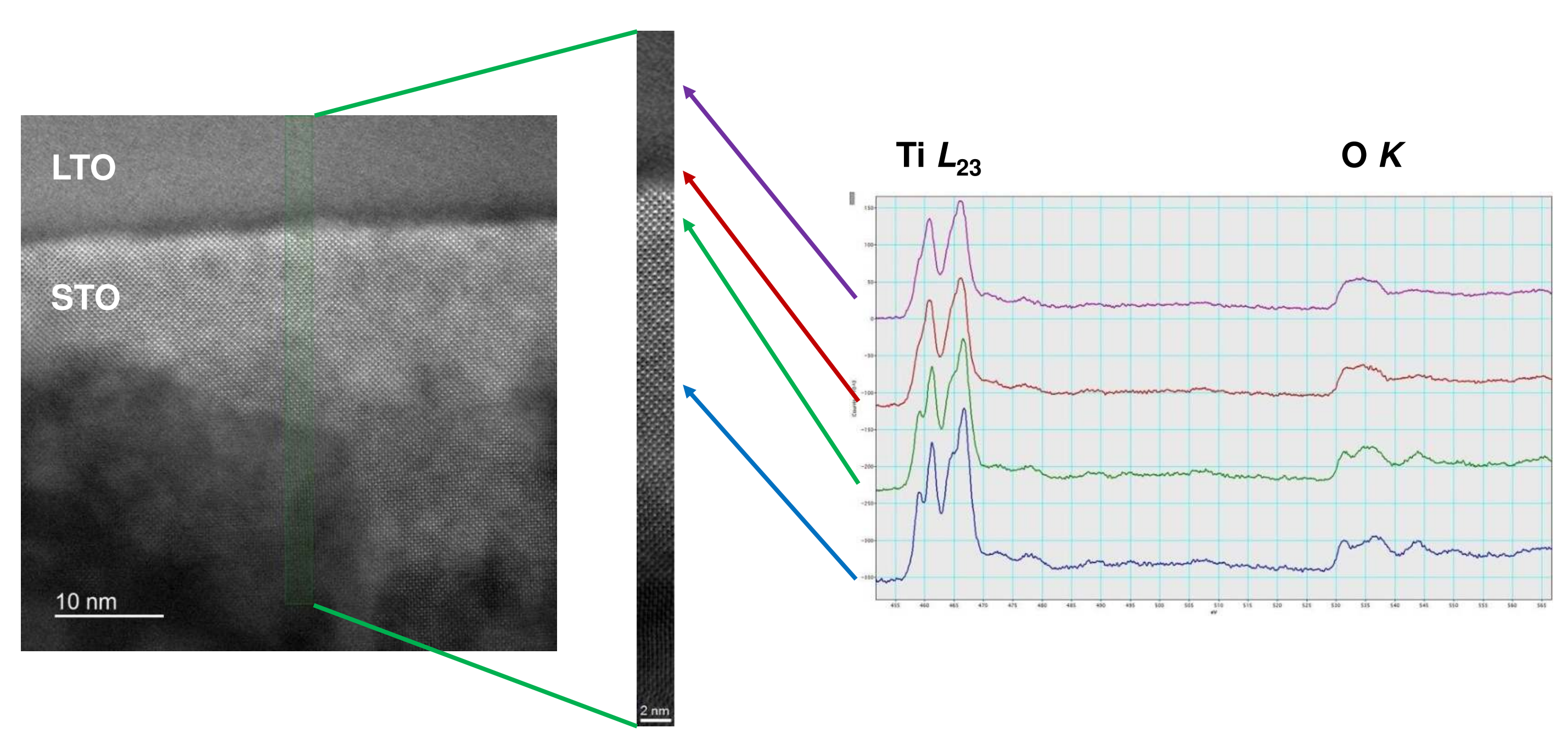

- The irradiated STO band shows much more $\mathrm{Ti}^{3+}$ character 


\section{Evolution of the Interface Structure}

Pacific

Northwest

NATIONAL LABORATORY

Comparison of EELS analysis on LTO As-Grown and at 4 dpa:
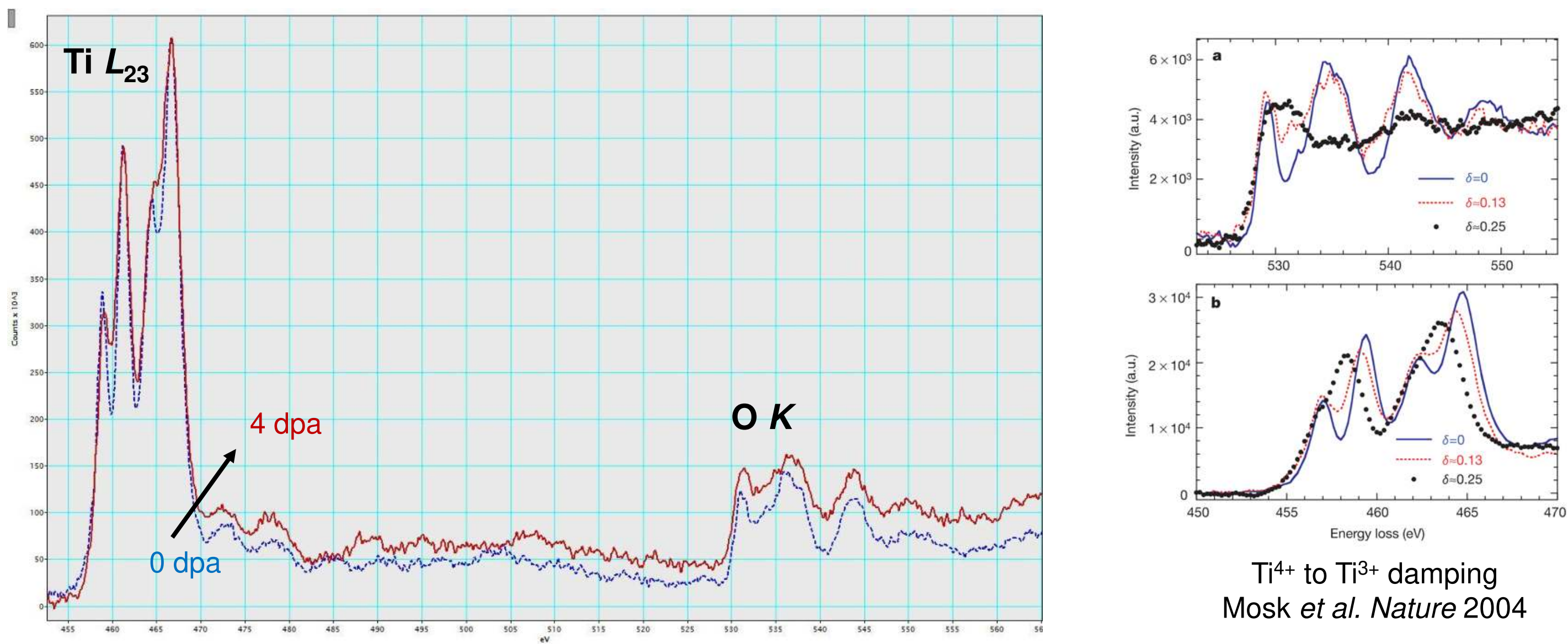

$\mathrm{Ti}^{4+}$ to $\mathrm{Ti}^{3+}$ damping Mosk et al. Nature 2004

- Points toward the presence of extensive oxygen vacancies 
Pacific

Northwest

Atomic-Level Description of the Interface Configuration

\section{$\mathrm{La}_{2} \mathrm{Ti}_{2} \mathrm{O}_{7} / \mathrm{STO}(110)$ interface}

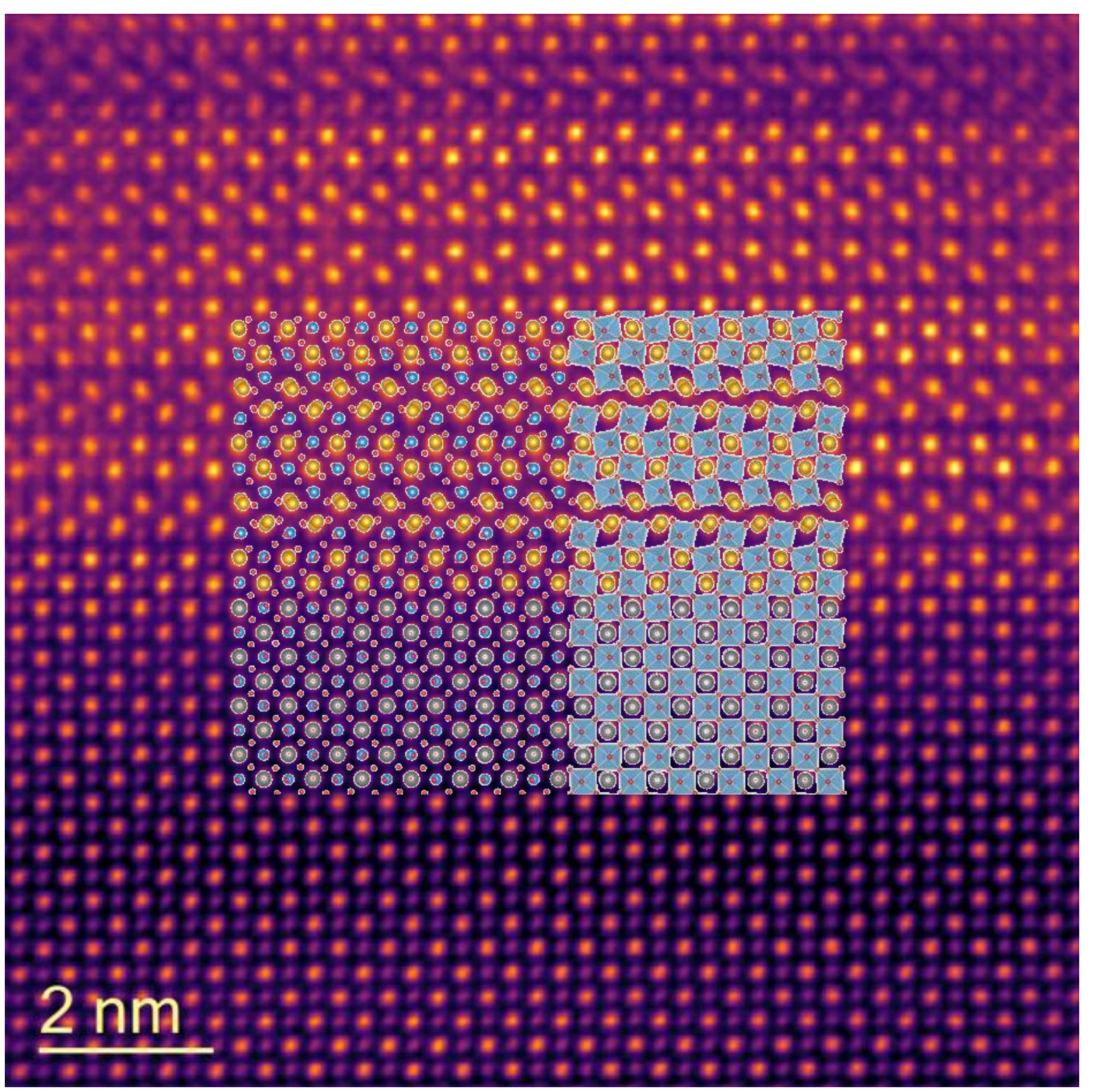

$\mathrm{LaTiO}_{3} / \mathrm{STO}(110)$ interface

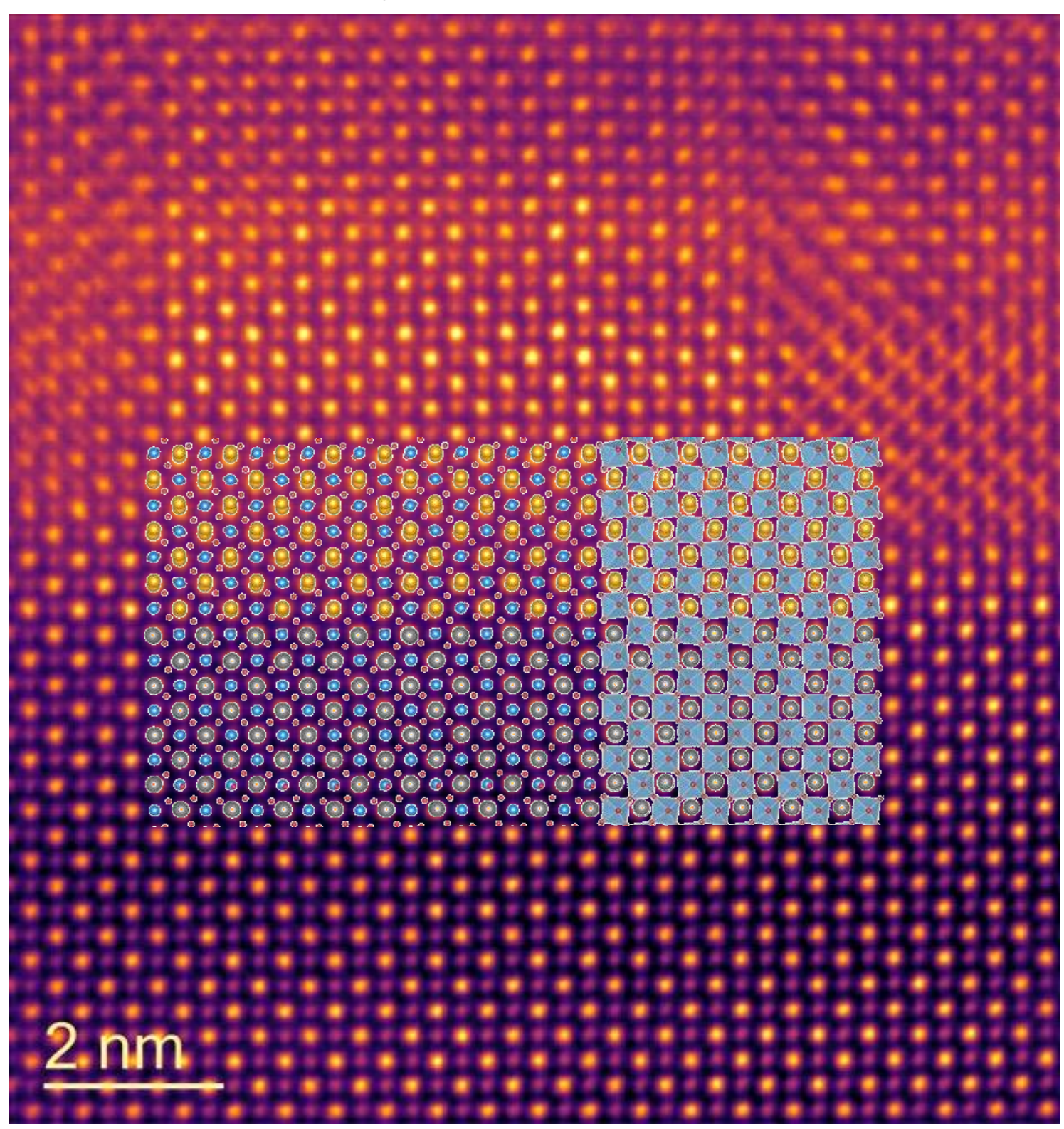


Pacific Northwest

\section{$\mathrm{La}_{2} \mathrm{Ti}_{2} \mathrm{O}_{7} / \mathrm{STO}(110)$ interface}

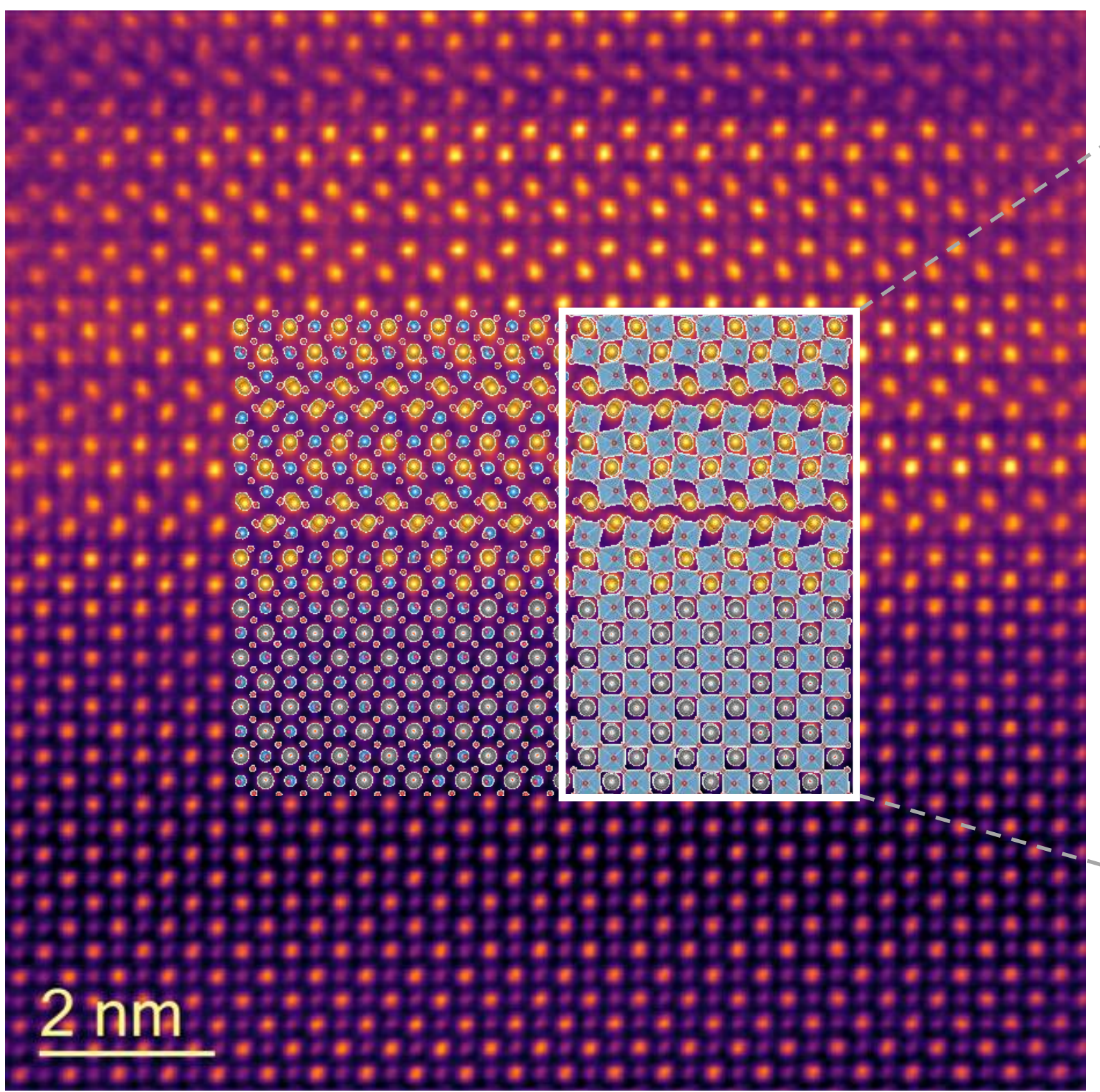

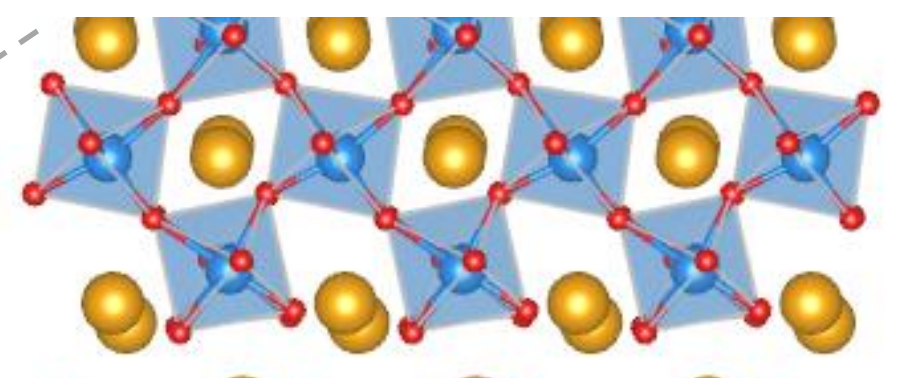
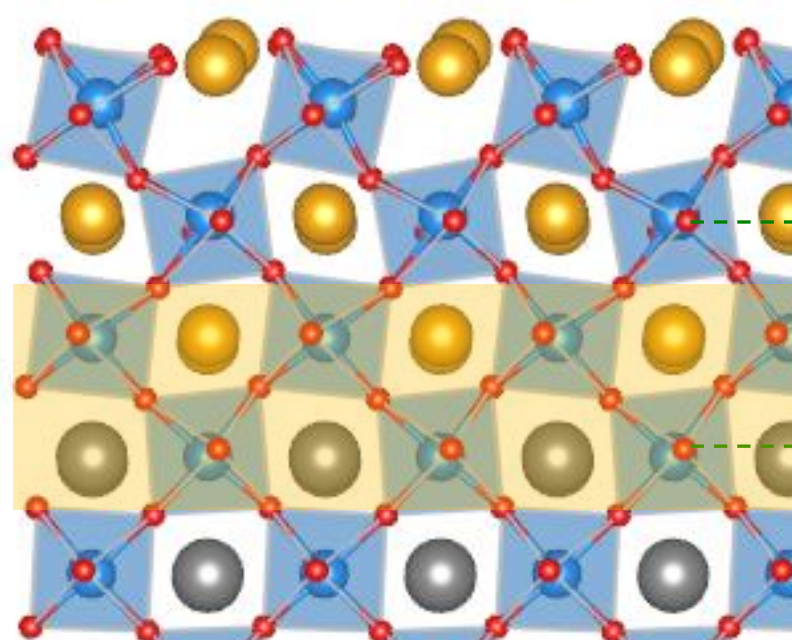

- 90

$5050 \% 0.5$

- a o a 0 o-

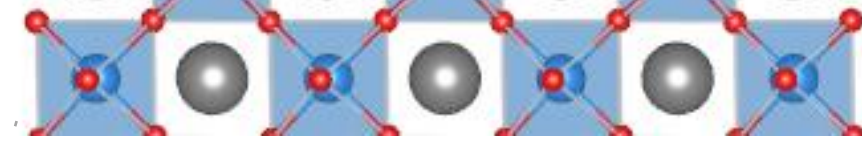

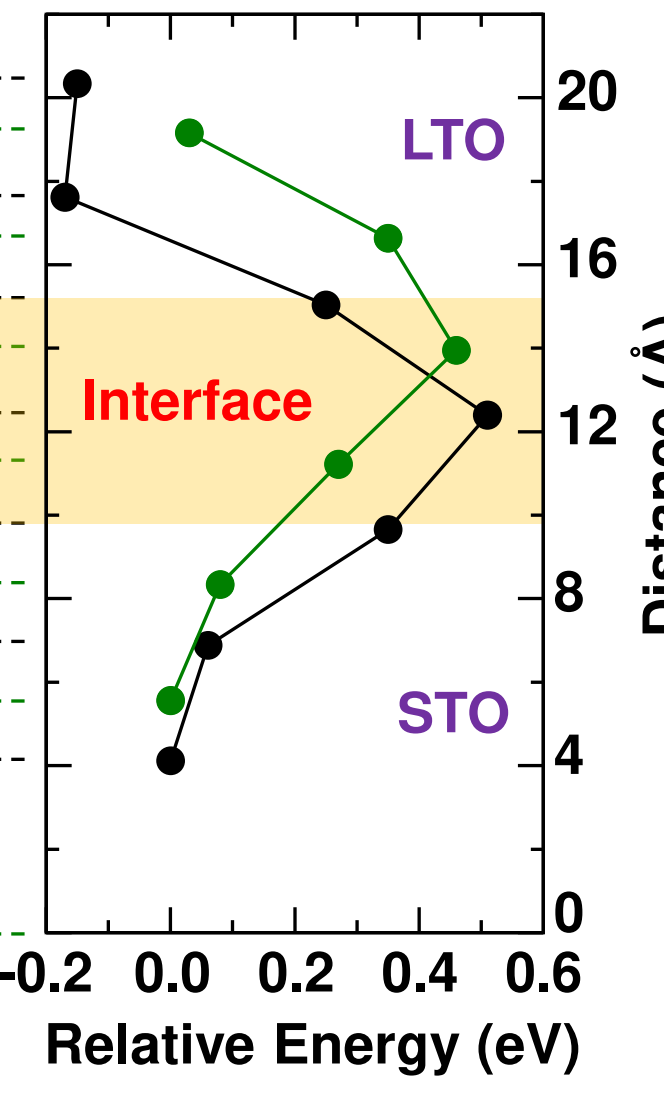

- Less energetically favorable to have $V_{O}$ at the interface

- $V_{O}$ would accumulate at LTO interlayers and in bulk STO 


\section{Summary}

Northwest

- STEM: The film/substrate interface is more damage resistant than the film and substrate.

- PACBED: Interface remains crystalline while film and substrate are amorphous.

- EELS: Highlight the presence of extensive oxygen vacancies at the interface.

- $\boldsymbol{A b}$ initio Simulations: Formation of $O$ vacancies less favorable at the interface.

$\circ$ The energetics for $O$ vacancy formation follow the amorphization sequence observed experimentally: film $\rightarrow$ substrate $\rightarrow$ interface.

FULL PAPER

Asymmetric Lattice Disorder Induced at Oxide Interfaces

Steven R. Spurgeon,* Tiffany C. Kaspar, Vaithiyalingam Shutthanandan, Jonathan Gigax, Lin Shao, and Michel Sassi

*Spurgeon et al., Adv. Mater. Interfaces, 2020, 1901944 [DOI: https://doi.org/10.1002/admi.201901944] 


\section{Acknowledgments}

Pacific

Northwest

NATIONAL LABORATORY

$\square$ Financial Support: NPSI - PNNL

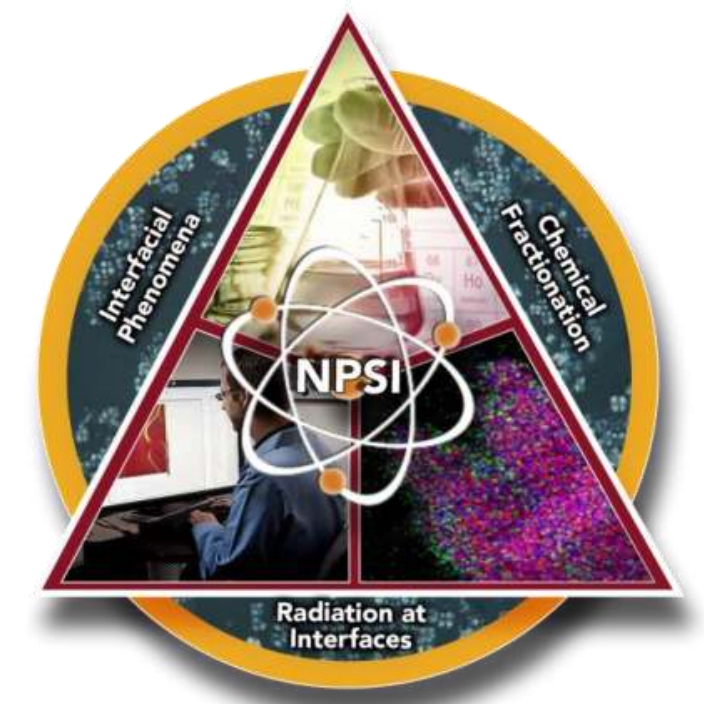

Computational Resources:

Constance cluster at PNNL

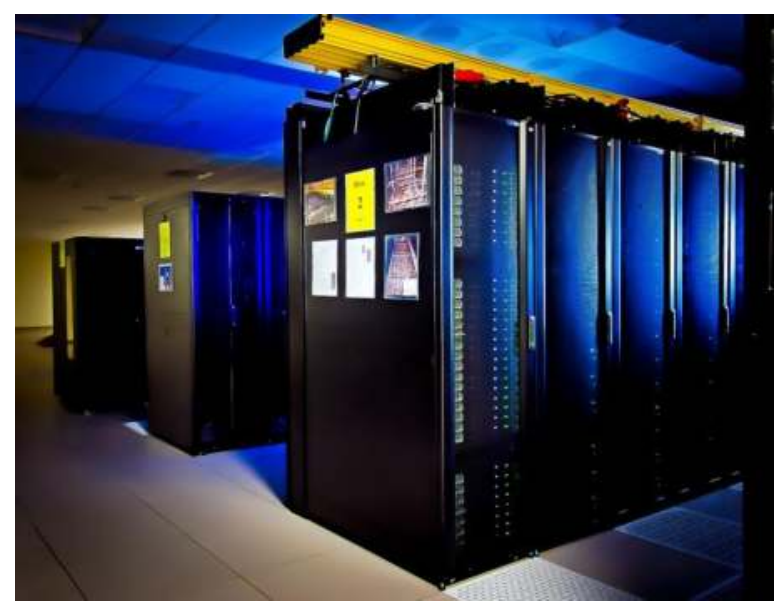


Pacific

Northwest

Thank you

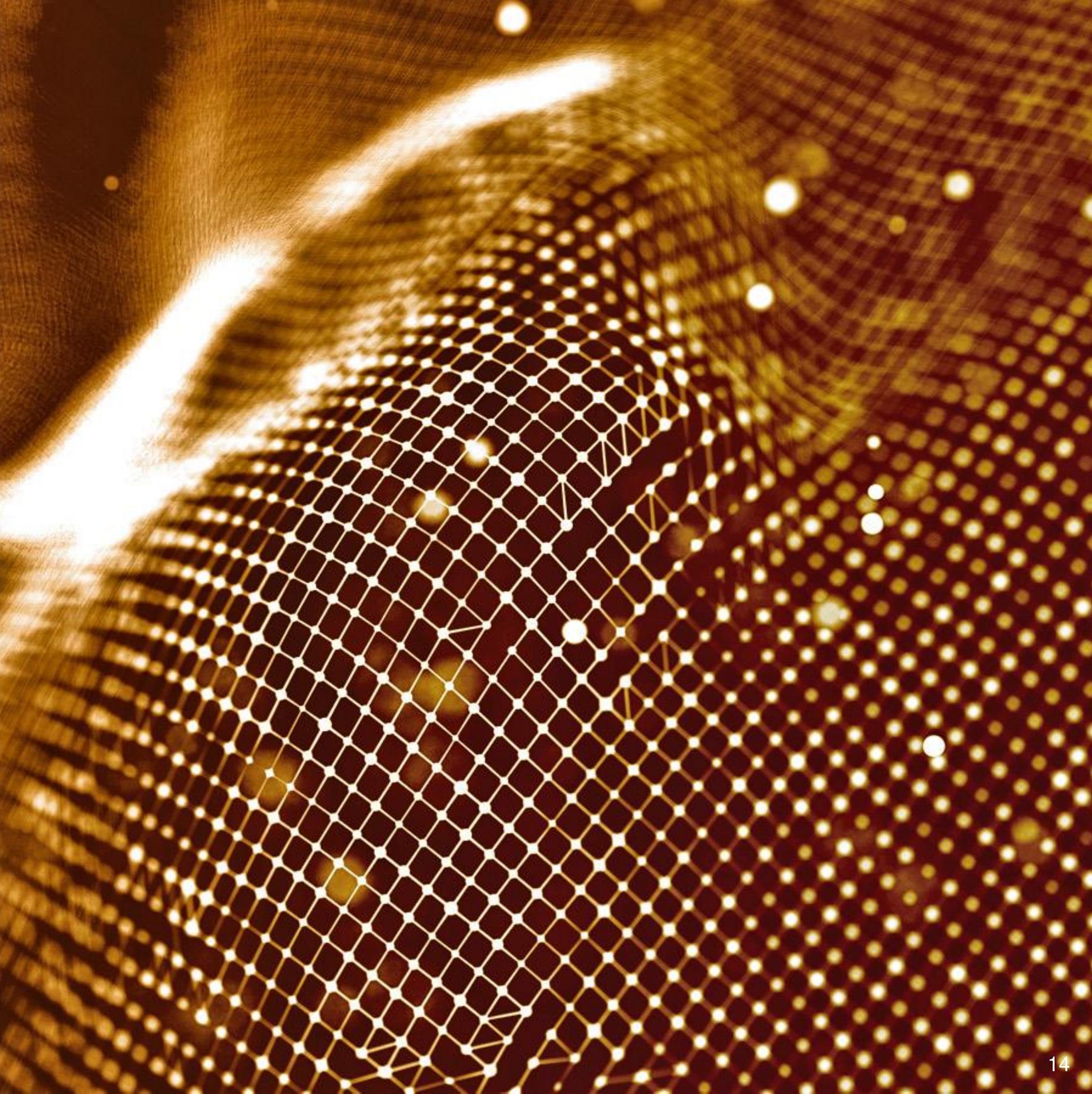

